\title{
The Impact of Cultural Symbols and Spokesperson Identity on Attitudes and Intentions
}

\section{Detailed Report}

\section{Introduction}

In recent decades, many countries have witnessed a rapid increase of ethnic and cultural diversity within their population and understanding minority consumers has become a priority for marketers. Standard approaches have emerged in the area of so-called ethnic marketing. In terms of media planning, advertisers attempt to reach consumers when their ethnic identity is most salient. This is consistent with the argument that ethnic identity primes positively affect responses to targeted advertisements among socially distinctive groups (e.g. Forehand and Deshpandé, 2001; Forehand, Deshpandé and Reed, 2002; Chattaraman, Rudd and Lennon 2009; Dimofte, Forehand and Deshpandé 2003). In terms of copy writing, targeted ads typically feature spokespeople or models with the same ethnic background as the target. They are thought to have a positive impact on advertisement evaluation (e.g. Aaker, Brumbaugh, and Grier 2000; Antioco et al. 2012; Brumbaugh and Grier 2006; Deshpandé and Stayman 2004; Green 1999; Grier and Brumbaugh 1999; Grier and Deshpandé 2001; Martin, Lee, and Yang 2004; Whittler, 1991).

These strategies assume that ethnic groups are homogeneous. Yet, not all minority consumers identify with their host and heritage cultures to the same degree. We argue that generational status is one of the most important factors that determine the effectiveness of these standard minority targeting approaches. Second-generation minority consumers constitute a growing demographic, representing, for example, 10\% of the Dutch population (Centraal Bureau voor de Statistiek 2012) and 11\% of the US population (U.S. Census Bureau 2010). These consumers often consider both the heritage and the mainstream culture to play an important part in their lives (Arends-Toth and van de Vijver, 2004): they are more likely than their parents to 
identify as biculturals (Giguère, Lalone and Lou 2010), which impacts their consumption patterns. The objective of this paper is to demonstrate the importance of consumers' generational status for the effectiveness of minority targeting practices. We conduct replications of the two standard paradigms described above and show that generational status constitutes an important boundary condition for these strategies.

\section{Generational Status and ethnic identity priming}

The influence of identity on consumer behavior has been discussed in many different streams of research (Reed et al. 2012). According to Donthu and Cherian (1994), ethnic identity is the key variable mediating the impact of ethnicity on shopping behavior. For the bicultural, ethnic identity is situational: the salience of a given identity is affected by the situation in which choices are made (Stayman and Deshpandé 1989). This means that it can be affected by primes. Identity primes - specific cues in the environment that cause a particular identity to become salient - have been shown to affect consumption-related behavior, particularly regarding identityrelevant products (Kettle and Häubl 2011; Reed 2004; White and Dahl 2007). The literature has highlighted the positive impact of ethnic primes on minority consumers' responses to targeted advertisements through increased ethnic identity salience (Forehand and Deshpandé 2001; Forehand, Deshpandé and Reed 2002; Chattaraman, Rudd and Lennon 2009; Dimofte, Forehand and Deshpandé 2003). We argue that the impact of priming on ethnic identity salience and, subsequently, on the effectiveness of targeted advertisements is in fact significantly stronger for second-generation, bicultural minority consumers than for first-generation minority consumers, whose ethnic identity tends to be chronically salient. In light of this, we expect ethnic identity primes to have a more positive impact on responses to ethnic ads in second-generation than in 
first-generation minority consumers. In this study, we discuss the impact of ethnic identity primes on consumers' response to a same-ethnicity spokesperson.

2.1. Study design and procedure

Participants for this study were 106 consumers of Chinese heritage living in a major Dutch city and approached through professional and civic organizations, such as the Chinese student association, as well as through other participants. Fifty-two participants (42\% male, mean age: 38.3 years old) were first-generation Chinese immigrants while 54 (57\% male, mean age: 23.4 years old) were born in the Netherlands to Chinese parents. Participants were randomly assigned to either the prime or the control condition and presented with a paper booklet containing four print advertisements that they were asked to evaluate. One of these ads featured a female Chinese model acting as a spokesperson for a telephone service provider (Figure. 1a). In the ethnic prime condition, this stimulus was immediately preceded by an advertisement of the Hong Kong Tourism Board (Figure 1b) featuring Chinese cultural symbols (e.g., a dragon, young girls in traditional dress, etc.). In the control condition, no culturally specific images were shown. The other advertisements were fillers. Respondents' attitude towards, and identification with the Chinese spokesperson were measured through 6- and 3-items scales respectively (I find the person in the advertisement friendly, happy, intelligent, trustworthy, attractive, appealing; “The person in the advertisements looks like me”, “I identify with the person in the advertisement”, "The person in the advertisement has the same ethnic background as me"). After handing in the first questionnaire, participants received a second booklet containing demographic, ethnicity and culture-related questions. A modified version of the Suinn-Lew Asian Self-Identity Acculturation Scale (SL-ASIA - Suinn et al. 1987, 1992) was used to assess the degree of acculturation of the participants. A low score on the SL-ASIA indicates high identification with Asian culture and low acculturation to Western culture; a high score reflects the opposite. 


\subsection{Results}

\subsubsection{Attitude towards the same-ethnicity spokesperson}

The items were averaged to create an index $(\alpha=0.89)$. The two-way ANOVA showed a significant main effect of both generation $(F(2,102)=17.20, p<.001)$ and ethnic prime $(F(1$, $102)=59.37, p<.001$ ) on attitude towards the minority spokesperson (Figure 2a). There was a significant interaction effect between ethnic prime and generational status $(F(2,101)=15.56, p<$ .001) on attitude (Table 1). First- and second-generation respondents were affected differently by the prime. When exposed to the ethnic prime, the attitude towards the ethnic spokesperson was similar in first $(M=5.19, S D=0.54)$ and second-generation respondents $(M=5.15, S D=0.58)$. However, when not exposed to the prime, attitude was significantly lower for second- $(M=3.40$, $S D=0.96)$ than for first-generation individuals $(M=4.62, S D=0.94)$. An analysis of simple effects showed that the effect of prime was significant both for second-generation subjects $(F(1$, $102)=69.18, p<.001)$ and for first-generation subjects $(F(1,102)=6.94, p=.01)$.

\subsubsection{Identification with the same-ethnicity spokesperson}

The items were averaged to create an index $(\alpha=0.88)$. A second two-way ANOVA showed a significant main effect of both generation $(F(1,102)=13.29, p<.001)$ and ethnic prime $(F(1,102)=45.98, p<.001)$ on identification with the ethnic spokesperson (Table 1$)$. There was a significant interaction effect between ethnic prime and generational status $(F(1,102)$ $=27,10, p<.001$ ) on identification, with identification with the spokesperson being similar in first $(M=4.93, S D=0.92)$ and second-generation respondents $(M=5.26, S D=0.77)$ when they were exposed to the ethnic prime but significantly lower for second- $(M=2.70, S D=1.42)$ than for first-generation individuals $(M=4.59, S D=1.19)$ when they were not exposed to the prime (Figure 2b). An analysis of simple effects showed that the effect of prime was significant for 
second generation subjects $(F(1,102)=73.23, p<.001)$ but not for first generation subjects $(F(1$, $102)=1.22, p=.27)$. These results confirm our hypothesis.

\subsubsection{Acculturation}

There was a significant $(t(104)=-11.08 ; p<.001)$ difference in scores on the SL-ASIA scales between the first-generation $(M=2.29 ; S D=0.64)$ and the second-generation $(M=3.56$; $S D=0.54)$ participants, indicating that second-generation Chinese individuals identified significantly more with Western culture and less with Asian culture. The SL-ASIA score did not mediate the effect of prime. We speculate that the reason for this is that the SL-ASIA scale is a bipolar scale that reflects a one-dimensional approach to acculturation: it assumes that identification with the mainstream culture is negatively correlated with identification with the ethnic culture. In other words, this scale does not account for biculturalism and thus does not allow isolating the effect of ethnic and mainstream identification. In Study 2 we will use a different scale with separate unipolar scales for ethnic and mainstream identification.

\subsection{Discussion}

These results indicate that first-generation migrants are less sensitive to ethnic identity primes than second-generation individuals. This means that the impact of ethnic identity priming or cultural context on minority consumers' reactions to targeted advertisements is likely to be greater for the second generation. When looking to use ethnic appeals targeting the secondgeneration population, advertisers should benefit from doing so in a context in which their ethnic identity is salient (e.g. when they are at home rather than at work or school). When targeting these consumers, it is important to choose the right cultural context given that they are likely to be less sensitive to ethnic appeals if their ethnic identity is not activated. However, when targeting a first-generation population, the context is likely to make less of a difference. 


\section{Generational status and spokesperson ethnicity}

According to distinctiveness theory (Deshpandé and Stayman 1994; Grier and Deshpandé 2001), members of socially distinctive minority groups tend to have a more salient ethnic identity than members of majority groups. This results in a greater impact of targeted advertising featuring same-ethnicity spokespeople on minority consumers' responses to advertisements (Deshpandé and Stayman, 1994). Several studies have shown a positive impact of spokespeople of the same ethnicity on distinctive consumers' attitudes towards the brand and ad (e.g. Aaker, Brumbaugh, and Grier 2000; Antioco et al. 2012; Green 1999; Martin, Lee, and Yang 2004; Whittler, 1991), and ethnic spokespeople or models are widely used in targeted advertising. We argue that first-generation minority consumers tend to have a more salient ethnic identity than second-generation minority consumers. Because of this, this strategy is significantly more effective when targeting first-generation minority consumers than when targeting secondgeneration minority consumers. We predict that this effect of generational status on the effectiveness of the strategy is mediated by the strength of identification with the heritage culture. 3.1. Study design and procedure

Participants for this study were 270 consumers of Turkish heritage living in a major Dutch city. The mean age was 35.89 years old; 52\% were female. One hundred forty-three participants (53\%, mean age: 41.52 years old) were first-generation Turkish immigrants while 127 (47\%, mean age: 29.51 years old) were born in the Netherlands to Turkish parents. Participants were approached at their home and completed a paper or online questionnaire. Twenty-two percent of the participants filled the questionnaire online; there was no significant effect of response medium on the dependent variables. Six respondents were deleted from the sample because of missing data. For the measurement of identification with the host and the heritage culture, we relied on the Vancouver Acculturation Index (VAI; Ryder et al. 2000), a 
scale that takes into account the bi-dimensional nature of acculturation and can be adapted to different ethnic groups. The VAI considers identification with both the host and the heritage culture; unlike the SL-ASIA scale, it does not assume that the two are negatively correlated. For both cultures, the same items are rated on a five-point scale. Items included statements such as "I would be willing to marry a Turkish person”, “I would be willing to marry a Dutch person”; “I enjoy typical Turkish jokes and humor”, "I enjoy typical Dutch jokes and humor", etc. Participants were randomly assigned to a Turkish prime, a Dutch prime or the control condition. In the Turkish and Dutch conditions, respondents were asked to select the most representative symbols of the culture among cultural icons. In the control condition, participants selected three pictures among natural landscapes. Similar manipulations have been used successfully in the past (e.g., Hong et al 2000). Respondents were asked to rate an advertisement for a charity, the charity itself, their willingness to support it and the spokesperson. The ethnicity of the young man in the advertisement was manipulated: he was assigned either a Turkish (“Ali Oztürk”) or a Dutch name ("Frank de Jong"). The stimuli were otherwise identical (Figure 3a and 3b). Participants completed the VAI and answered questions regarding their ethnic identity and demographics.

\subsection{Results}

\subsubsection{Attitude towards the ad}

The items were averaged to create an index $(\alpha=0.93)$. The two-way ANOVA revealed a main effect of generation $(F(1,266)=9.93, p=.002)$ on attitude towards the ad, with firstgeneration participants rating ads higher on average $(M=4.05, S D=1.21)$ than secondgeneration participants $(M=3.63, S D=1.08)$, but no main effect of spokesperson heritage $(F(1$, 266) $=0.08, p=.78$ ). There was a significant interaction effect between generational status and spokesperson heritage on attitude towards the ad $(F(1,266)=8.24, p=.004)$ indicating that the effect of spokesperson heritage varies significantly according to the person's generational status 
(Figure 4a). For first-generation participants, attitude towards the ad was more positive when the spokesperson had a Turkish name $(M=4.26, S D=1.17)$ than a Dutch one $(M=3.84, S D=1.04)$. The opposite was true of second-generation participants who rated the ad with a Dutch spokesperson $(M=3.80, S D=1.08)$ higher than the ad with a Turkish spokesperson $(M=3.46$, $S D=1.06$.) An analysis of simple effects showed that the effect of spokesperson ethnicity was significant for first-generation participants $(F(1,266)=5.27, p=.022)$ and marginally significant for second-generation participants $(F(1,266)=3.17, p=.076)$.

The priming effect was not replicated: there was no significant effect of priming on attitude towards the ethnically targeted ad in either the first $(F(2,258)=0.54, p=0.59)$ or the second $(F(2,258)=0.09, p=0.92)$ generation. We are not certain what caused this lack of effect; the cultural icons may have been too stereotypical or have negative connotations. A marginally significant interaction effect between prime, generation and spokesperson ethnicity $(F(2,258)=$ 2.82; $p=.062$ ) reflected a significant effect of the priming condition on second-generation participants' attitude towards the Dutch ad $(F(2,258)=4.42 ; p=0.013)$. Second-generation participants exposed to both the Dutch or the Turkish prime rated it higher (Dutch: $M=4.12, S D$ $=0.75$; Turkish: $M=4.05, S D=1.04)$ than those exposed to the control condition $(M=3.22, S D$ $=1.22$ ). This suggests that ethnic identity primes accentuate positive feelings towards the host culture in second-generation consumers, but the data does not allow us to draw firm conclusions.

\subsubsection{Attitude towards the organization}

The scale items were averaged to create an index $(\alpha=0.86)$. The two-way ANOVA revealed no main effect of either generation $(F(1,266)=0.57, p=.45)$ or spokesperson heritage $(F(1,266)=0.47, p=.50)$ on attitude towards the organization. There was a significant interaction effect between generational status and spokesperson ethnicity $(F(1,266)=9.76, p=$ .002). For first-generation participants, attitude towards the organization was more positive when 
its spokesperson had a Turkish name $(M=5.03, S D=0.69)$ than a Dutch one $(M=4.70, S D=$ 0.64), while the opposite was observed in second-generation participants who rated the organization with a Dutch spokesperson $(M=4.90, S D=0.78)$ higher than the organization with a Turkish spokesperson $(M=4.69, S D=0.74)$; Figure $4 \mathrm{~b}$. An analysis of simple effects showed that the effect of spokesperson ethnicity was significant for first-generation participants $(F(1$, 266) $=7.71, p=.006)$ and marginally significant for second-generation participants $(F(1,266)=$ 2.81, $p=.095)$. Consistent with the findings described above, there was a marginally significant interaction effect between prime, generation and spokesperson identity $(p=.096)$.

\subsubsection{Attitude towards the spokesperson}

The items were averaged to create an index $(\alpha=0.90)$. The two-way ANOVA revealed a main effect of generation $(F(1,266)=13.83, p<.001)$ on attitude towards the spokesperson, with first-generation participants expressing more positive attitudes $(M=4.70, S D=0.79)$ than second-generation participants $(M=4.33, S D=0.91)$, but no main effect of spokesperson heritage $(F(1,266)=0.11, p=.75)$. There was a significant interaction effect between generational status and spokesperson heritage on attitude towards the spokesperson $(F(1,266)=$ 31.78, $p<.001)$. First-generation participants rated the Turkish spokesperson $(M=4.95, S D=$ 0.75) higher than the Dutch one $(M=4.44, S D=0.74)$. The opposite was true of secondgeneration participants who rated the Dutch spokesperson $(M=4.63, S D=0.71)$ higher than the Turkish one $(M=4.04, S D=0.91$. $)$; Figure 4c. An analysis of simple effects showed that the effect of spokesperson ethnicity was significant for both first-generation $(F(1,266)=15.00, p<$ $.001)$ and second-generation subjects $(F(1,266)=16.77, p<.001)$. There was a marginally significant interaction effect between prime, generation and spokesperson identity $(F(1,258)=$ 2.42, $p=.091)$.

\subsubsection{Willingness to support}


The two items were averaged to create an index $(\alpha=0.56)$. The two-way ANOVA did not reveal any main effect of either generation $(F(1,266)=0.23, p=.64)$ or spokesperson heritage $(F(1,266)=0.96, p=.33)$ on willingness to support the organization. There was a significant interaction effect between generational status and spokesperson ethnicity $(F(1,266)=4.07, p=$ .045). For first-generation participants, willingness to support was higher when the spokesperson was Turkish $(M=2.56, S D=0.47)$ than when he was Dutch $(M=2.40, S D=0.38)$. For secondgeneration participants, on the other hand, willingness to support was higher when the spokesperson was Dutch $(M=2.48, S D=0.48)$ than when he was Turkish $(M=2.43, S D=0.42)$

; Figure 4d. An analysis of simple effects showed that the effect of spokesperson ethnicity was significant for first-generation $(F(1,266)=4.77, p=.030)$ but not for second-generation subjects $(F(1,266)=0.51, p=.48)$. There was no significant three-way interaction with priming $(F(2$, 258) $=0.47, p=.63)$.

\subsubsection{Strength of identification with the heritage culture}

A one-way ANOVA revealed a significant main effect of generation on strength of identification with the heritage culture $(F(1,268)=50.51, p<.001)$. First-generation participants identified more strongly with Turkish culture $(M=4.20, S D=0.40)$ than second-generation participants $(M=3.90, S D=0.27)$. There was no significant main effect of the priming condition on the strength of identification with the heritage culture $(F(2,264)=0.62, p=.54)$. A second one-way ANOVA also revealed a significant main effect of generation on identification with the mainstream culture $(F(1,268)=61.98, p<.001)$, with second-generation participants identifying more strongly with Dutch culture $(M=3.77, S D=0.42)$ than first-generation participants $(M=$ 3.38, $S D=0.38)$ and no significant effect of the priming condition $(F(2,264)=1.05, p=.35)$.

\subsubsection{Mediation analysis}


A mediation analysis was conducted using Preacher, Rucker, and Hayes' (2007) MODMED macro to investigate whether the effect of generational status on attitude towards a targeted ad was mediated by strength of ethnic identity. We expected generational status to influence ethnic identification and ethnic identification to influence advertising responses, but only when the ad featured an ethnic spokesperson. Thus, we predicted a moderated mediation where spokesperson heritage moderates the Mediator-DV relationship. The mediation analysis revealed a significant main effect of generation on ethnic identification (mediator variable model: $b=-0.30, S E=0.04, t(265)=-7.11, p<.001)$ and a significant identification by spokesperson heritage interaction effect (dependent variable model: $b=1.37, S E=0.34, t(265)=4.00, p<$ .001), which indicates that spokesperson heritage moderates the effect of ethnic identification on attitude towards the ad. After adding the mediator, the effect of generation on attitude was no longer significant $(b=-0.24, S E=0.14, t(265)=-1.70, p=.09)$. A bootstrap analysis of indirect effect confirmed a significant mediation effect (95\% confidence interval: $-0.17<$ C.I. $<-0.15$ ). Strength of identification with the host culture did not mediate the effect.

\subsection{Discussion}

These results confirm that there is an effect of generational status on response to ethnic appeals, such as same-ethnicity spokespeople, and that this effect is mediated by acculturation as measured by the Vancouver Acculturation Index. Of central interest, we observed that the decisive mediating factor is not the strength of identification with the host culture, but rather the strength of identification with the heritage culture. This is consistent with our contention that ethnic identification is of crucial importance to understand the effect of targeted advertising on second-generation biculturals.

\section{Conclusion}


In today's multicultural societies, targeted advertising constitutes an important tool for marketers. Two studies have shown that generational status constitutes an important boundary condition for at least two popular targeted advertising strategies. In the first study, we saw that the responses of second-generation, bicultural consumers who switch from one identity to the other tend to be more affected by ethnic identity primes that activate their heritage identity than first-generation consumers. Marketers should take this into account when planning to target second-generation consumers using ethnic appeals, and consider the context in which the communication will appear. In the case of first-generation consumers, context is likely to make less of a difference. In the second study, we showed that generational status significantly affects responses to targeted advertising featuring same-ethnicity spokespeople. The strategy of using ethnic spokespeople in advertising was only beneficial among first-generation consumers. In fact, in our study we found a negative effect for second-generation consumers. Further research is needed to test the robustness and generalizability of this reversal. Nevertheless, the results were consistent across dependent variables, raising interesting questions for future research. We speculate that the negative effect among second-generation consumers in this particular case may be connected to negative stereotypes about the ethnic minority in Dutch culture. It is likely however that there is some variation in second-generation consumers' degree of identification with their heritage and their mainstream culture, with processes such as consumer disidentification (Josiassen, 2011) leading to different marketplace consequences. The generational status by spokesperson ethnicity interaction was fully mediated by strength of identification with the ethnic culture, but not by identification with the mainstream culture.

In addition to serving as a warning to both researchers and practitioners regarding the dangers of holding simplistic assumptions about the relative homogeneity of ethnic minorities, our studies also have more specific implications. The results of Study 1 suggest that the positive 
effects of ethnic identity cues often demonstrated in the literature depend on the level of chronic accessibility of the target identity. The results of Study 2 expand on the recent findings of Antioco et al. (2012) in several ways. For example, they highlight the role of differences within the same ethnic minority and show the process by which identification processes explain variation in the effectiveness of ethnic spokespeople and models in targeted advertising. In a world of increasing ethnic diversity, we believe that these findings constitute an important addition to the existing literature on targeted advertising. We hope that they will encourage the development of targeted advertising practices that better take into account the complexity of today's ethnic identities. 


\section{References}

Aaker, J.L., Brumbaugh, A.M. and Grier, S.A. (2000). Nontarget Markets and Viewer Distinctiveness: The Impact of Target Marketing on Advertising Attitudes. Journal of Consumer Psychology, 9(3), 127-140.

Antioco, M., Vanhamme, J., Hardy, A. and Bernardin, L. (2012). On the importance of social integration for minority targeting effectiveness. International Journal of Research in Marketing, 29(4), 380-389.

Brumbaugh, A.M. and Grier, S.A. (2006). Insights from a "Failed" Experiment: Directions for Pluralistic, Multiethnic Advertising Research. Journal of Advertising, 35(3), 35-46.

Centraal Bureau voor de Statistiek (2012). Population - Migration and Migrants. http://statline.cbs.nl/StatWeb/, accessed November 2, 2012.

Chattaraman, V., Rudd, N. A., and Lennon, S. J. (2009). Identity salience and shifts in product preferences of Hispanic consumers: Cultural relevance of product attributes as a moderator. Journal of Business Research, 62(8), 826-833.

Deshpandé, R. and Stayman, D.M. (1994). A Tale of Two Cities: Distinctiveness Theory and Advertising Effectiveness. Journal of Marketing Research, 31(1), 57-64.

Dimofte, C.V., Forehand, M.R. and Deshpandé, R. (2003). Ad schema incongruity as elicitor of ethnic self-awareness and differential advertising response. Journal of Advertising, 32(4), 7-17.

Donthu, N. and Cherian, J. (1994). Impact of strength of ethnic identification on Hispanic shopping behavior. Journal of Retailing, 70(4), 384-394.

Forehand, M. R. and Deshpandé, R. (2001). What we see makes us who we are: Priming ethnic self-awareness and advertising response. Journal of Marketing Research, 38(3), 338-346. 
Forehand, M. R., Deshpandé, R., and Reed, A.I. (2002). Identity salience and the influence of differential activation of the social self-schema on advertising response. Journal of Applied Psychology, 87(6), 1086-1099.

Giguère, B., Lalone, R., Lou, E. (2010). Living at the Crossroads of Cultural Worlds: The Experience of Normative Conflicts by Second Generation Immigrant Youth. Social and Personality Psychology Compass, 4(1), 14-29.

Green, C.L. (1999). Ethnic Evaluations of Advertising: Interaction Effects of Strength of Ethnic Identification, Media Placement, and Degree of Racial Composition. Journal of Advertising, 28(1), 49-64.

Grier, S.A. and Brumbaugh, A.M. (1999). Noticing Cultural Differences: Ad Meanings Created by Target and Non-Target Markets. Journal of Advertising, 28(1), 79-93.

Grier, S.A. and Deshpandé, R. (2001). Social Dimensions of Consumer Distinctiveness: The Influence of Social Status on Group Identity and Advertising Persuasion. Journal of Marketing Research, 38(2), 216-224.

Hong, Y., Morris, M. W., Chiu, C.Y., and Benet-Martínez, V. (2000). Multicultural minds: A dynamic constructivist approach to culture and cognition. American Psychologist, 55(7), 709-720.

Josiassen, A. (2011). Consumer Disidentification and Its Effects on Domestic Product Purchases : An Empirical Investigation in the Netherlands. Journal of Marketing, 75(2), 124-140.

Kettle, K.L. and Häubl, G. (2011). The Signature Effect: Signing Influences ConsumptionRelated Behavior by Priming Self-Identity. Journal of Consumer Research, 38(3), 474489.

Martin, B.A.S., Lee, C.K.C, and Yang, F. (2004). The influence of ad model ethnicity and selfreferencing on attitudes. Journal of Advertising, 33(4), 27-37. 
Preacher, K. J., Rucker, D. D., \& Hayes, A. F. (2007). Assessing moderated mediation hypotheses: Theory, methods, and prescriptions. Multivariate Behavioral Research, 42, $185-227$.

Reed, A. (2004). Activating the Self-importance of Consumer Selves: Exploring Identity Salience Effects on Judgments. Journal of Consumer Research, 31(2), 286-295.

Reed, A. II, Forehand, M.R., Puntoni, S., and Warlop, L. (2012). Identity-based consumer behavior. International Journal of Research in Marketing, 29, 310-321.

Ryder, A., Alden, L.E., and Paulhus, D.L. (2000). Is acculturation unidimensional or bidimensional? A head-to-head comparison in the prediction of personality, self-identity, and adjustment. Journal of Personality and Social Psychology, 79(1), 49-65.

Stayman, D.M. and Deshpandé, R. (1989). Situational ethnicity and consumer behavior. Journal of Consumer Research, 16(3), 361-371.

Suinn, R.M., Rickard-Figueroa, K., Lew, S., and Vigil, P. (1987). The Suinn-Lew Asian SelfIdentity Acculturation Scale: An initial report. Educational and Psychological Measurement, 47(2), 401-407.

Suinn, R.M., Ahuna, C., and Khoo, G. (1992). The Suinn-Lew Asian Self-Identity Acculturation Scale: Concurrent and factorial validation. Educational and Psychological Measurement, 52(4), 1041-1046.

U.S. Census Bureau (2010). Nation's Foreign-Born Population Nears 37 Million. http://www.census.gov/newsroom/releases/archives/foreignborn_population/cb10159.html, accessed November 2, 2012.

White, K. and Dahl, D.W. (2007). Are All Out-Groups Created Equal? Consumer Identity and Dissociative Influence. Journal of Consumer Research, 34(4), 525-536. 
Whittler, T.E. (1991). The Effects of Actors' Race in Commercial Advertising: Review and Extension. Journal of Advertising, 20(1), 54-60. 


\section{TABLES}

Table 1

\begin{tabular}{|c|c|c|c|c|c|c|c|c|}
\hline Prime & \multicolumn{4}{c|}{ No prime } & \multicolumn{4}{c|}{ Prime } \\
\hline Generation & \multicolumn{2}{|c|}{ First } & \multicolumn{2}{c|}{ Second } & \multicolumn{2}{c|}{ First } & \multicolumn{2}{c|}{ Second } \\
\hline & $M$ & $S D$ & $M$ & $S D$ & $M$ & $S D$ & $M$ & $S D$ \\
\hline $\begin{array}{c}\text { Attitude towards } \\
\text { spokesperson }\end{array}$ & 4.62 & 0.94 & 3.40 & 0.96 & 5.19 & 0.54 & 5.15 & 0.58 \\
\hline $\begin{array}{c}\text { Identification with } \\
\text { spokesperson }\end{array}$ & 4.59 & 1.19 & 2.70 & 1.42 & 4.93 & 0.92 & 5.26 & 0.77 \\
\hline
\end{tabular}

Table 2

\begin{tabular}{|c|c|c|c|c|c|c|c|c|}
\hline \multirow{2}{*}{ Generation } & \multicolumn{4}{c|}{ First } & \multicolumn{3}{c|}{ Second } \\
\hline Spokesperson heritage & \multicolumn{2}{|c|}{ Turkish } & \multicolumn{2}{c|}{ Dutch } & \multicolumn{2}{c|}{ Turkish } & \multicolumn{2}{c|}{ Dutch } \\
& $M$ & $S D$ & $M$ & $S D$ & $M$ & $S D$ & $M$ & $S D$ \\
\hline Attitude towards the ad & 4.26 & 1.17 & 3.84 & 1.04 & 3.46 & 1.06 & 3.80 & 1.08 \\
\hline Attitude towards the organization & 5.03 & 0.69 & 4.70 & 0.64 & 4.69 & 0.74 & 4.90 & 0.78 \\
\hline Attitude towards the spokesperson & 4.95 & 0.75 & 4.44 & 0.74 & 4.04 & 0.91 & 4.63 & 0.71 \\
\hline Willingness to support & 2.56 & 0.47 & 2.40 & 0.38 & 2.43 & 0.42 & 2.48 & 0.48 \\
\hline
\end{tabular}


Table 3

\begin{tabular}{|c|c|c|c|c|c|c|c|c|c|c|c|c|c|c|c|c|c|c|c|c|c|c|c|c|}
\hline Prime & \multicolumn{8}{|c|}{ Control } & \multicolumn{8}{|c|}{ Dutch } & \multicolumn{8}{|c|}{ Turkish } \\
\hline Generation & \multicolumn{4}{|c|}{ First } & \multicolumn{4}{|c|}{ Second } & \multicolumn{4}{|c|}{ First } & \multicolumn{4}{|c|}{ Second } & \multicolumn{4}{|c|}{ First } & \multicolumn{4}{|c|}{ Second } \\
\hline $\begin{array}{c}\text { Spokesperson } \\
\text { heritage }\end{array}$ & \multicolumn{2}{|c|}{ Dutch } & \multicolumn{2}{|c|}{ Turkish } & \multicolumn{2}{|c|}{ Dutch } & \multicolumn{2}{|c|}{ Turkish } & \multicolumn{2}{|c|}{ Dutch } & \multicolumn{2}{|c|}{ Turkish } & \multicolumn{2}{|c|}{ Dutch } & \multicolumn{2}{|c|}{ Turkish } & \multicolumn{2}{|c|}{ Dutch } & \multicolumn{2}{|c|}{ Turkish } & \multicolumn{2}{|c|}{ Dutch } & \multicolumn{2}{|c|}{ Turkish } \\
\hline & $M$ & $S D$ & $M$ & $S D$ & $M$ & $S D$ & $M$ & $S D$ & $M$ & $S D$ & $M$ & $S D$ & $M$ & $S D$ & $M$ & $S D$ & $M$ & $S D$ & $M$ & $S D$ & $M$ & $S D$ & $M$ & $S D$ \\
\hline $\begin{array}{c}\text { Attitude towards } \\
\text { the ad }\end{array}$ & 4.02 & 1.04 & 4.13 & 1.26 & 3.23 & 1.22 & 3.40 & 1.24 & 3.69 & 0.9 & 4.44 & 1.34 & 4.12 & 0.75 & 3.43 & 1.12 & 3.80 & 1.13 & 4.21 & 0.87 & 4.05 & 1.04 & 3.54 & 0.83 \\
\hline $\begin{array}{c}\text { Attitude towards } \\
\text { the organization }\end{array}$ & 4.83 & 0.37 & 4.76 & 0.95 & 4.85 & 1.13 & 4.58 & 0.59 & 4.51 & 0.8 & 5.25 & 0.56 & 4.94 & 0.54 & 4.62 & 0.92 & 4.76 & 0.59 & 5.08 & 0.34 & 4.93 & 0.57 & 4.88 & 0.65 \\
\hline $\begin{array}{c}\text { Attitude towards } \\
\text { the spokesp erson }\end{array}$ & 4.54 & 0.50 & 5.02 & 0.72 & 4.43 & 0.88 & 3.85 & 0.93 & 4.10 & 0.8 & 5.20 & 0.78 & 4.71 & 0.45 & 4.17 & 1.18 & 4.67 & 0.78 & 4.66 & 0.66 & 4.73 & 0.73 & 4.11 & 0.89 \\
\hline $\begin{array}{l}\text { Willingness to } \\
\text { support }\end{array}$ & 2.48 & 0.35 & 2.48 & 0.58 & 2.50 & 0.57 & 2.43 & 0.36 & 2.33 & 0.4 & 2.60 & 0.42 & 2.43 & 0.48 & 2.38 & 0.50 & 2.39 & 0.40 & 2.60 & 0.42 & 2.52 & 0.39 & 2.48 & 0.40 \\
\hline
\end{tabular}




\section{FIGURES}

Figure 1a

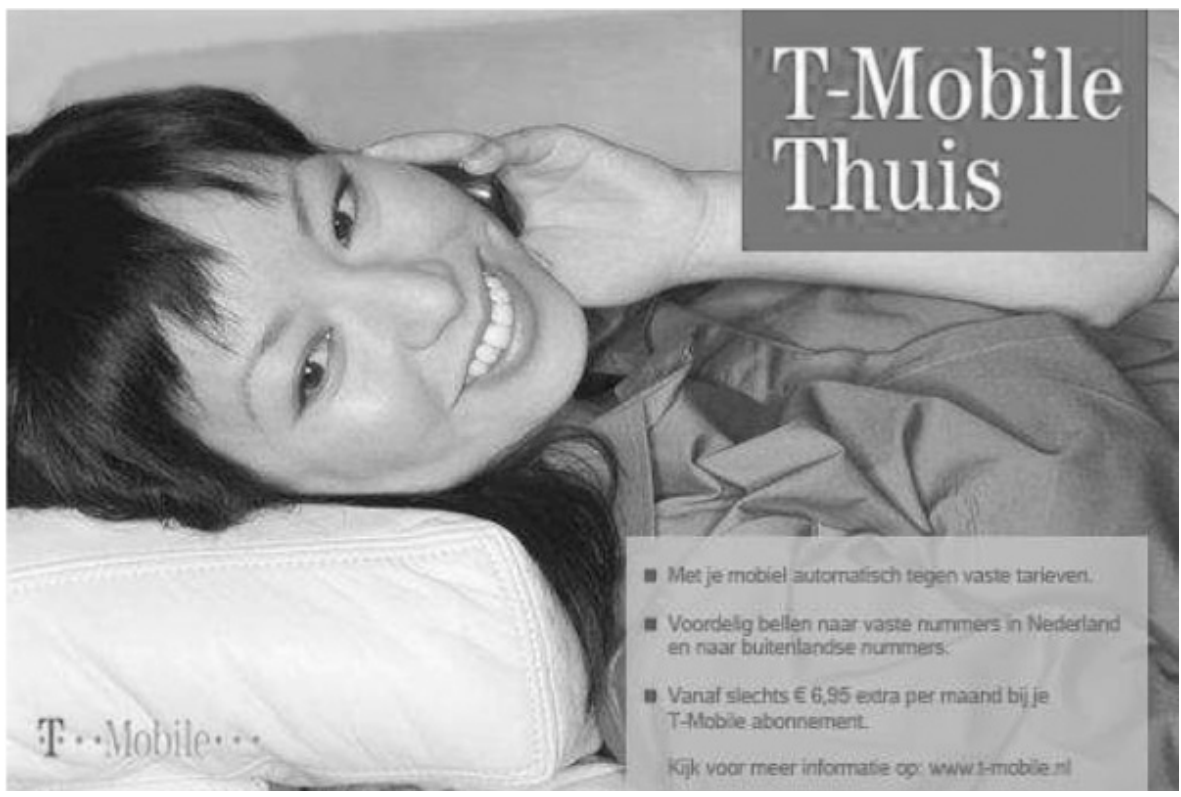

Figure $1 b$

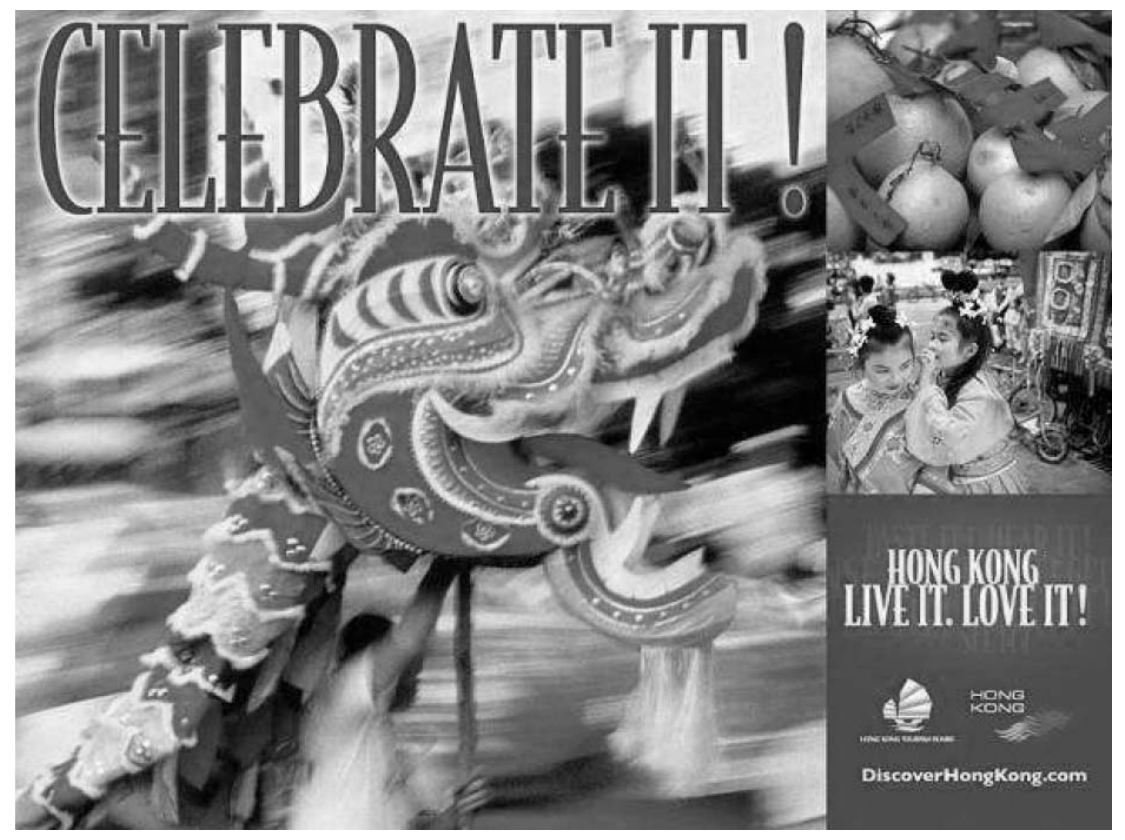


Figure $2 a$

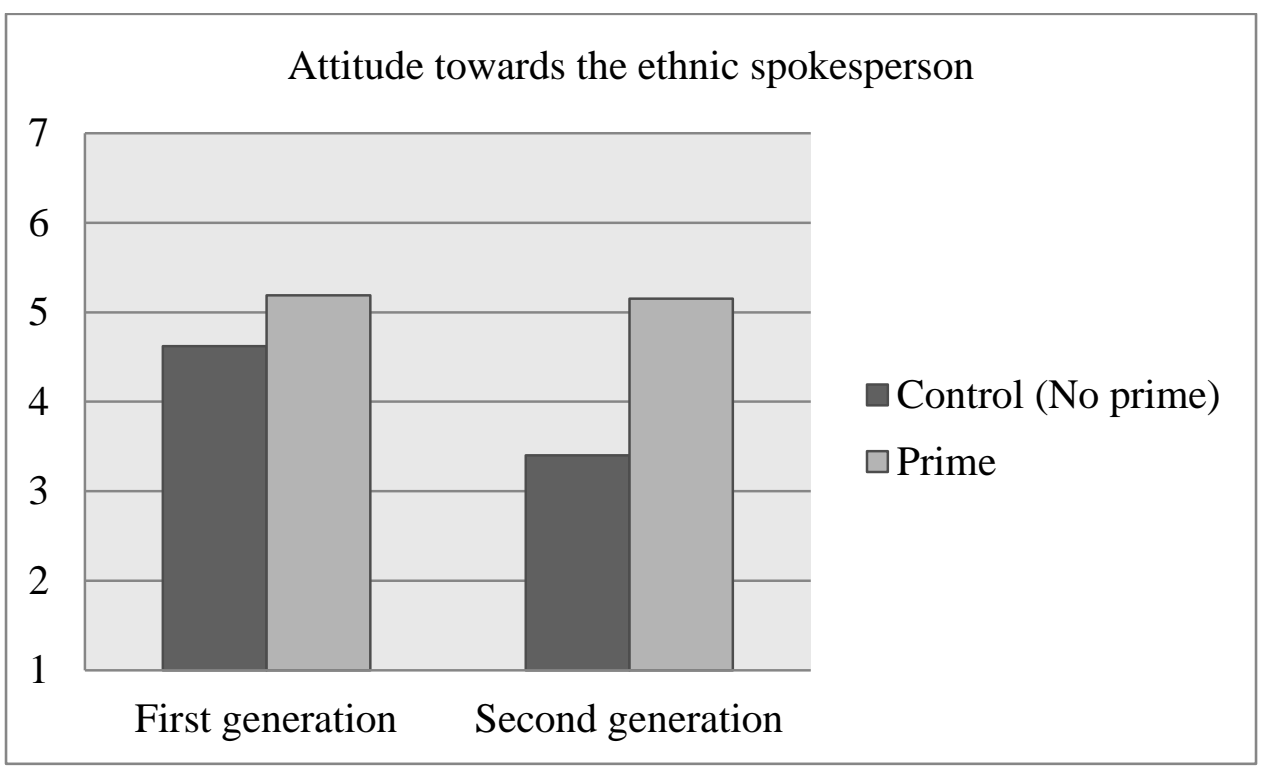

Figure $2 b$

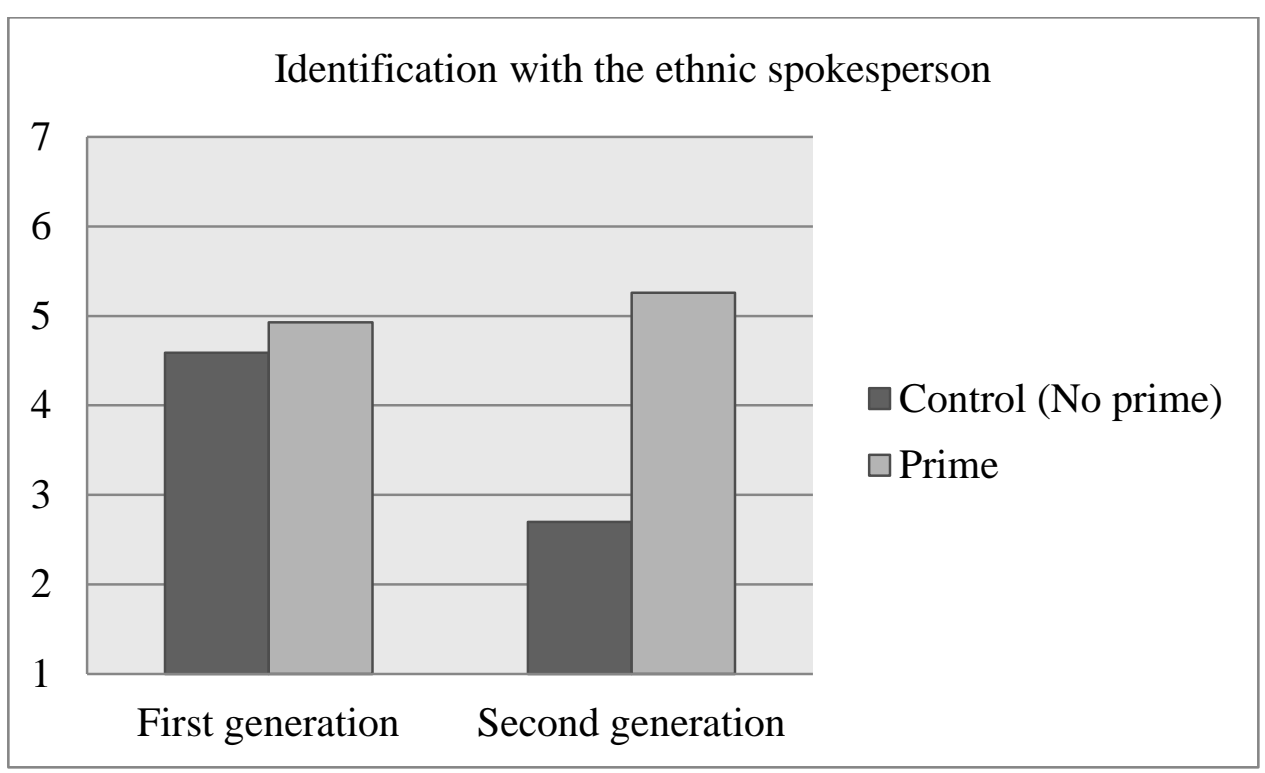


Figure $3 a$



Figure $3 b$

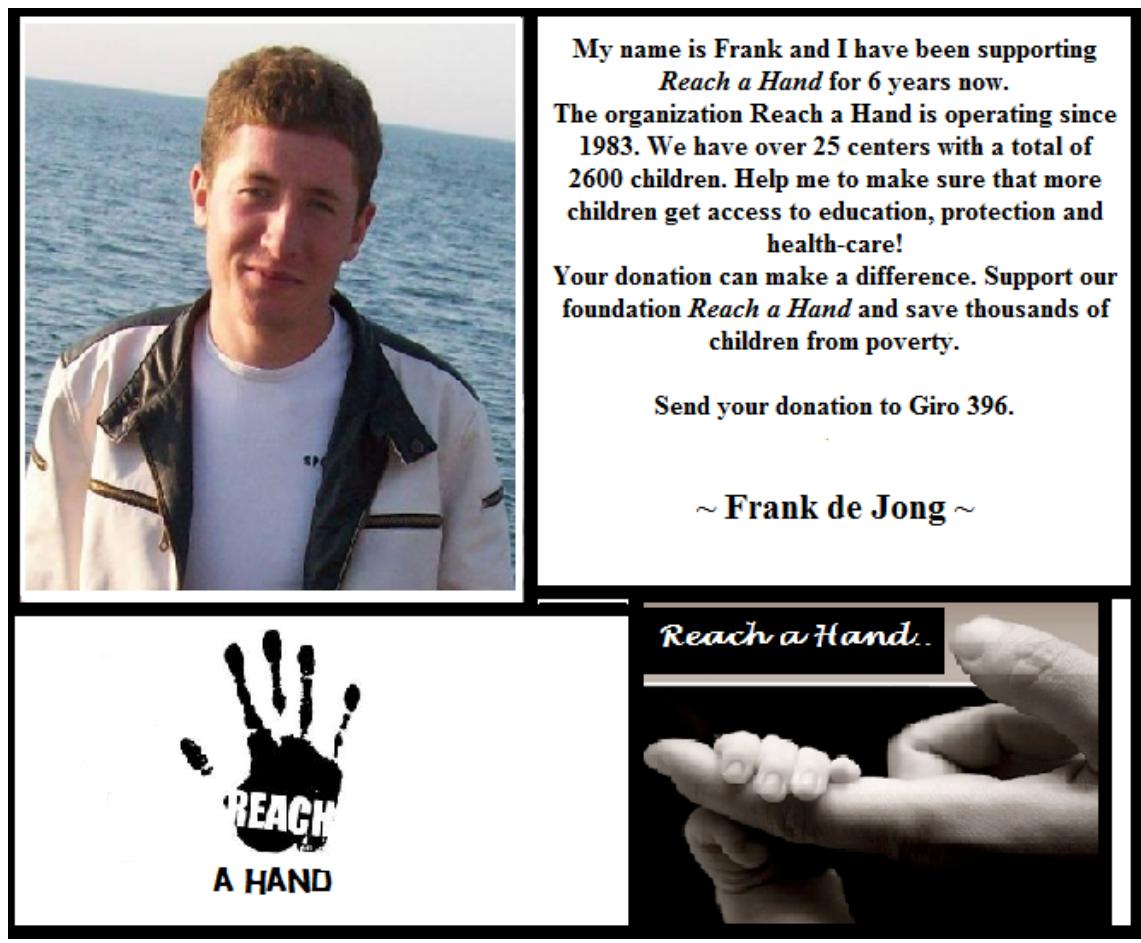


Figure $4 a$

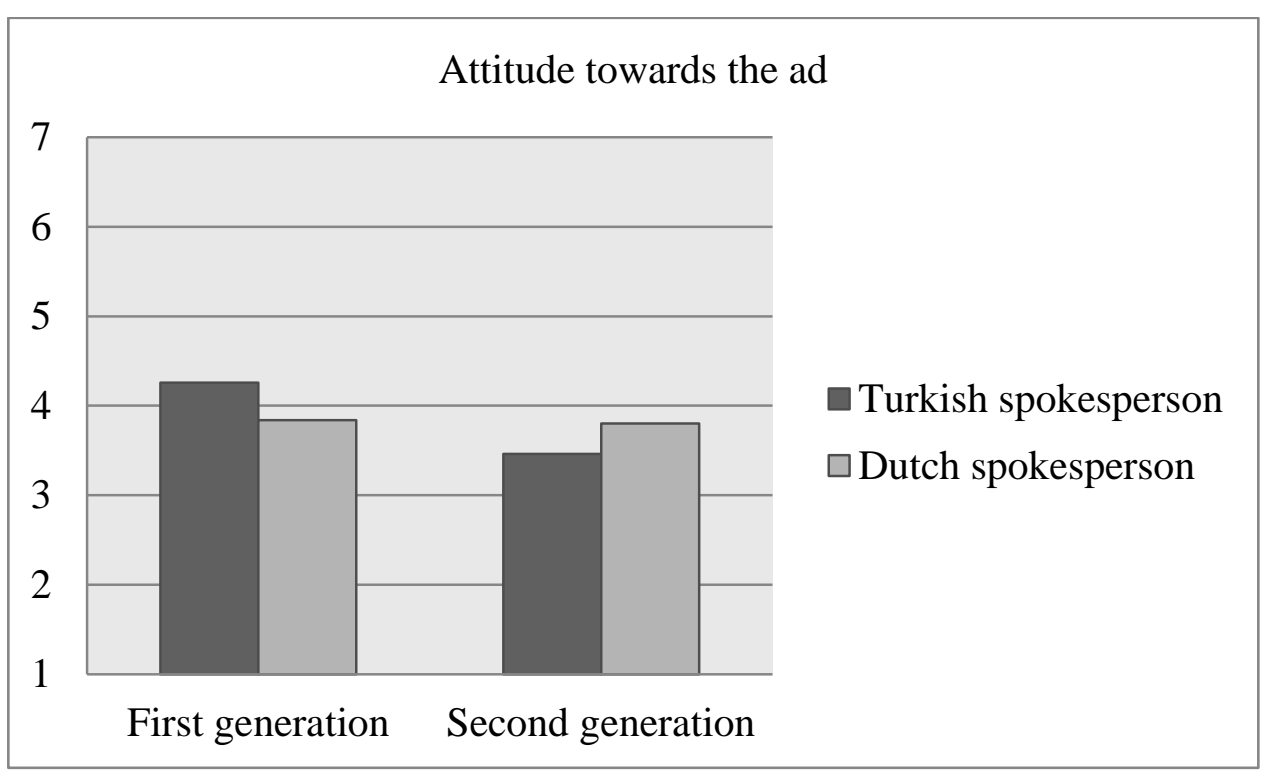

Figure $4 b$

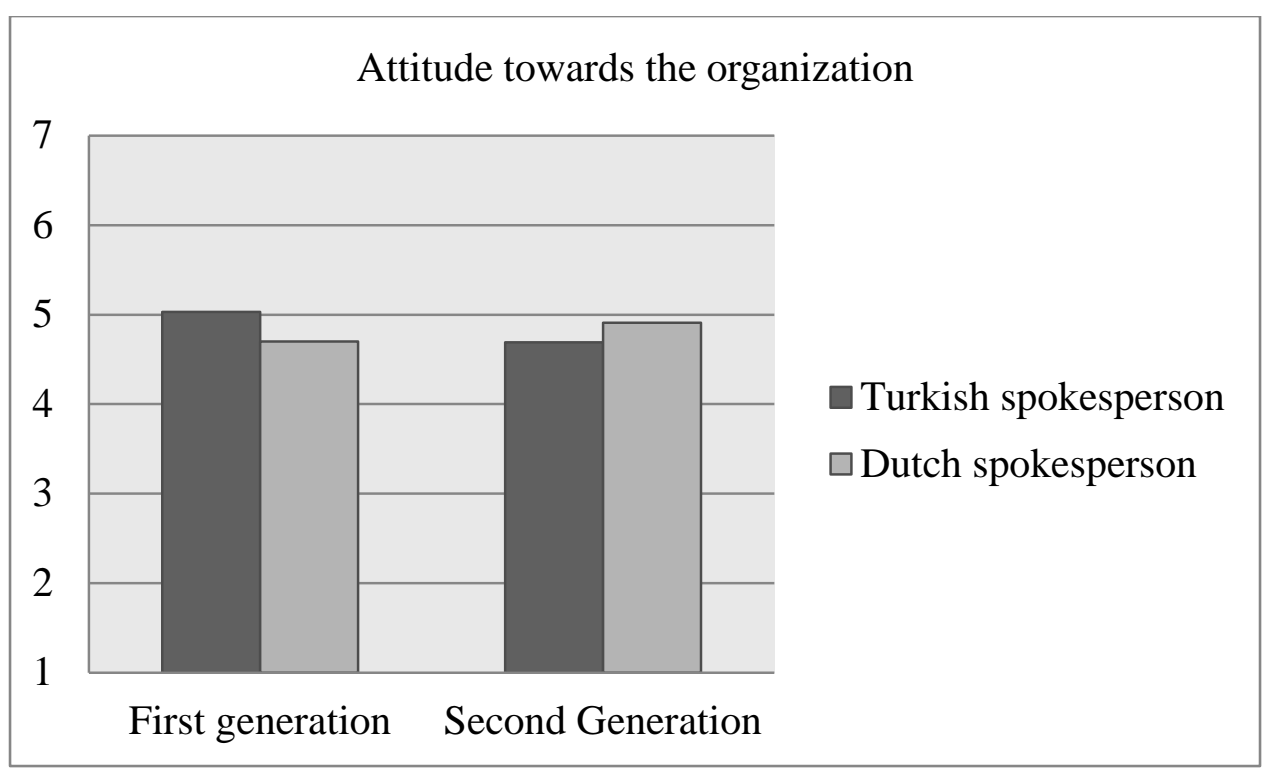


Figure 4c

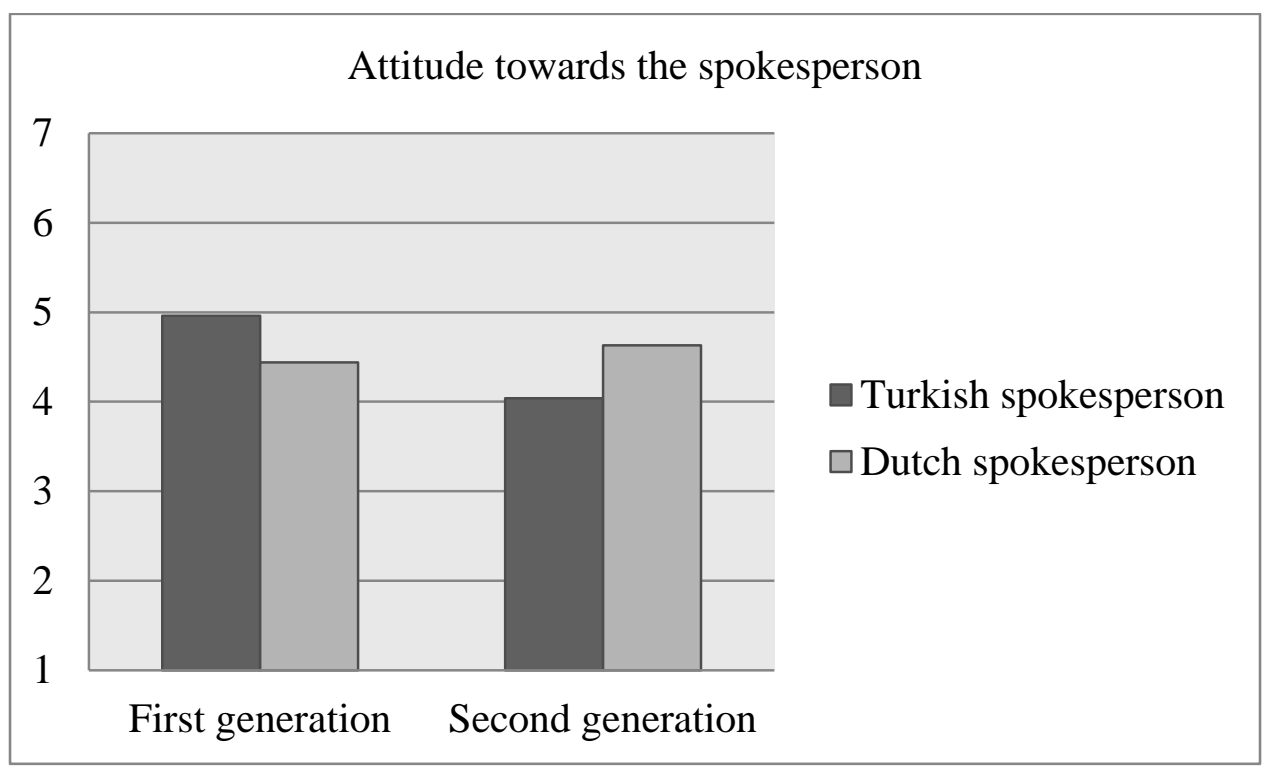

Figure 4d

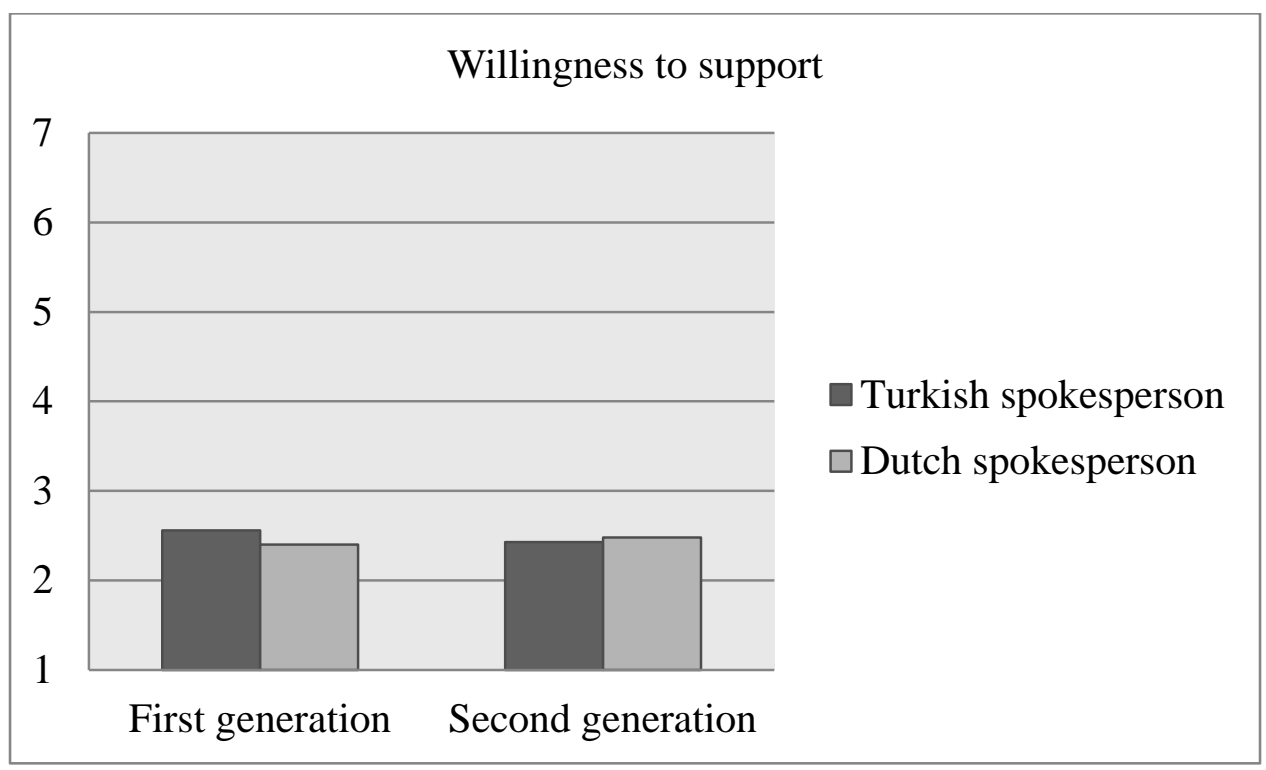

